\title{
On-pump versus off-pump coronary artery bypass surgery in patients older than 60 years: five-year follow-up of MASS III trial
}

Rodrigo Morel Vieira de Melo ${ }^{1,2,4}$, Whady Hueb ${ }^{1,2,3^{*}}$, Paulo Cury Rezende ${ }^{1,2}$, Eduardo Gomes Lima ${ }^{1,2}$, Alexandre Ciappina Hueb ${ }^{1,2}$, José Antonio Franchini Ramires ${ }^{1,2}$ and Roberto Kalil Filho ${ }^{1,2}$

\begin{abstract}
Background: We aim to evaluate in-hospital events and long-term clinical outcomes in patients over 60 years of age with stable coronary artery disease and preserved left ventricular ejection fraction undergoing off-pump or on-pump coronary artery bypass grafting.

Methods: The MASS III was a single-center randomized trial that evaluate 308 patients with stable coronary artery disease and preserved ventricular function assigned for: 155 to off-pump and 153 to on-pump CABG. Of this, 176 (58.3\%) patients were 60 years or older at the time of randomization ( 90 of-pump and 86 on-pump). The primary short-term end point was a composite of myocardial infarction, stroke, and overall mortality occurring within 30 days after surgery or before discharge, whichever was later. The primary long-term end point was death from any cause within 5 years, non-fatal myocardial infarction between 30 days and 5 years, or additional revascularization between 30 days and 5 years.
\end{abstract}

Results: On-pump CABG had a higher incidence of 30-day composite outcome than off-pump CABG (15,1\% and $5.6 \%$, respectively; $P=0.036)$. However, after the multivariate analysis, this association lost statistical significance, $P=0.05$. After 5-year follow-up, there were no significant differences between both strategies of CABG in the composite end points 16.7\% and 15.1\%; Hazard Ratio 1.07; Cl $0.41-1.82 ; P=0.71$, for off-pump and on-pump CABG respectively.

Conclusions: On-pump and off-pump CABG achieved similar results of combined events at short-term and 5-year follow-up.

Trial registration: Clinical Trial Registration Information-URL: http://www.controlled-trials.com. Registration number: ISRCTN59539154.

Keywords: Coronary artery disease, Coronary artery bypass grafts, CABG, Cardiopulmonary bypass, CPB

\section{Background}

Several studies comparing off-pump coronary artery bypass surgery (CABG) with on-pump CABG, in various patients populations, failure to demonstrate a superiority of a technique over the other in clinical outcomes despite some differences in postoperative complications [1-3]. Currently, there is an attempt to identify patient subgroups in whom

\footnotetext{
* Correspondence: mass@incor.usp.br

${ }^{1}$ Heart Institute (InCor) University of Sao Paulo, Sao Paulo, Brazil

${ }^{2}$ Department of Atherosclerosis, Heart Institute of the University of Sao Paulo, Sao Paulo, Brazil

Full list of author information is available at the end of the article
}

beating heart surgery is the preferred procedure, particularly in those with a high risk profile [4-6].

Advanced age is associated with a higher prevalence of preoperative comorbidities, reduced functional reserve, and increased mortality and morbidity in patients undergoing coronary artery bypass grafting $[7,8]$. That becomes a major concern as the number of elderly patients undergoing $\mathrm{CABG}$ surgery continues to increase $[9,10]$. Thus, recent trials addressed for this specific population, did not include data on long-term morbidity and mortality $[5,6]$.

The MASS III was a randomized clinical trial that evaluated postoperative outcomes and long-term clinical events in patients with multivessel coronary artery disease, stable

\section{Ciomed Central}

(c) 2014 Vieira de Melo et al.; licensee BioMed Central Ltd. This is an Open Access article distributed under the terms of the Creative Commons Attribution License (http://creativecommons.org/licenses/by/4.0), which permits unrestricted use, distribution, and reproduction in any medium, provided the original work is properly credited. The Creative Commons Public Domain Dedication waiver (http://creativecommons.org/publicdomain/zero/1.0/) applies to the data made available in this article, unless otherwise stated. 
angina, and preserved ventricular function, undergoing coronary artery bypass grafting with and without extracorporeal circulation [3].

The main finding of the MASS III trial was that either revascularization strategy provides similar rates of allcause mortality and major cardiovascular events at 5 years. The present post-hoc analysis aims to investigate whether off-pump CABG strategy would be especially advantageous for older patients undergoing CABG on postoperatively outcomes and long-term follow-up.

\section{Methods}

\section{Study design and treatment}

Protocol details have been published previously [11]. In brief, patients with angiographically documented proximal multivessel coronary stenosis of $>70 \%$ by visual assessment, stable angina, and preserved ventricular function were considered for inclusion. Patients were enrolled and randomized if the surgeons agreed that revascularization could be achieved by either strategy. All angiograms were reviewed, and a surgical plan was documented before randomization. Patients were eligible if they were referred for isolated coronary bypass surgery for the first time and an off-pump procedure was deemed technically feasible. In this post-hoc analysis, we included only patients with 60 years or older at the time of randomization. Patients were excluded if they required emergency or concomitant major surgery, unstable angina requiring emergency revascularization, ventricular aneurysm requiring repair, and a left ventricular ejection fraction of less than $40 \%$, previous stroke, peripheral vascular disease or chronic renal insufficiency with a estimated creatinine clearance of less than $60 \mathrm{~mL} / \mathrm{min}$. Patients were also excluded if they were unable to provide written informed consent. The Ethics Committee of the Heart Institute of the University of São Paulo - Medical School, in São Paulo Brazil, approved the trial, and all procedures were performed in accordance with the Helsinki Declaration. All subjects gave informed consent. Trial operators were required to perform optimum coronary revascularization in accordance with current best practices. The procedure was performed by surgeons experienced in both on-pump and off-pump bypass surgery. Stabilization devices were used during off-pump surgery to allow the safe construction of the anastomosis of the graft with the recipient artery.

\section{Qualification of surgeons}

Each operation was performed by a surgeon with more than 20 years of experience and having completed more than 100 procedures per year in both techniques.

\section{Study end points}

The primary short-term end point was a composite of myocardial infarction, stroke, and overall mortality occurring within 30 days after surgery or before discharge, whichever was later. The primary composite long-term end point was death from any cause within 5 years, non-fatal myocardial infarction between 30 days and 5 years, or additional revascularization between 30 days and 5 years. Stroke was defined as a focal brain injury that persisted for $>24$ hours, combined with an increase in disability of at least 1 grade on the Ranking scale [12]. Myocardial infarction within 7 days from the coronary artery bypass grafting procedure was considered if elevation of CK-MB or troponin 5 times or more the $99^{\text {th }}$ percentile.

\section{Follow-up}

Adverse and other clinical events were tracked from randomization. Patients were assessed with follow-up visits every 6 months at the Heart Institute.

\section{Statistical analysis}

All data were analyzed on an intention-to-treat principle beginning immediately after randomization. The risk of an event after on-pump surgery was compared with that after off-pump surgery, and the results are presented as the absolute difference with the corresponding 95\% confidence intervals. Values are expressed as mean $( \pm \mathrm{SD})$. Dichotomous data were compared by the $\chi^{2}$ statistic or Fisher exact test. Continuous variables that were not distributed normally, as evaluated through the Kolmogorov-Smirnov test, were compared by the Mann-Whitney test. Continuous variables with a normal distribution were compared by the Student's $t$ test. All reported probability values are 2 -sided. Event-free survival was graphically compared by using Kaplan-Meier curves. Event rates were compared with the use of the log-rank test of time to the first event after randomization. Relative risks were expressed as hazard ratios with associated confidence intervals and were derived from the Cox proportional-hazards model. A probability value of $P<0.05$ was considered statistically significant. Multivariable analysis with logistic regression (short-term end point) and Cox proportional-hazards model (long-term end point) were used when appropriated, including variables with a possible association $(P<$ $0.2)$ with the combined events. These analyses were performed with SPSS, version 17.0 (SPSS, Inc).

\section{Results}

Between March 2001 and March 2006, 308 patients with stable coronary artery disease were assigned to CABG: 153 to on-pump surgery and 155 to off-pump surgery. From those, 176 (58.3\%) patients were 60 years or older at the time of randomization (90 off-pump CABG and 86 on-pump CABG). The two groups were well-matched for baseline demographic, clinical, and angiographic characteristics and are summarized in Table 1 . The mean age was 65.7 in the on-pump patients and 67.1 in the off- 
Table 1 Baseline characteristics

\begin{tabular}{lccc}
\hline & $\begin{array}{c}\text { On-pump } \\
\text { CABG } \mathbf{n}=\mathbf{8 6}\end{array}$ & $\begin{array}{c}\text { Off-pump } \\
\text { CABG } \mathbf{n}=\mathbf{9 0}\end{array}$ & $\mathbf{P}$ \\
\hline Age (years) & $66.5 \pm 5.1$ & $67.9 \pm 5.1$ & 0.07 \\
Male gender n (\%) & $64(74.4)$ & $62(68.9)$ & 0.50 \\
Diabetes n (\%) & $32(37.2)$ & $29(32.2)$ & 0.029 \\
Hypertension & $58(67.4)$ & $61(67.8)$ & 1.0 \\
Current smoke n (\%) & $17(19.8)$ & $14(15.6)$ & 0.74 \\
Previous MI n (\%) & $35(40.7)$ & $44(48.9)$ & 0.29 \\
Angina n (\%) & $81(94.2)$ & $84(93.3)$ & 1.0 \\
Angina CCS III-IV n (\%) & $10(12.3)$ & $15(17.9)$ & 0.38 \\
Ejection fraction & $65.1 \pm 6.4$ & $65.8 \pm 9.3$ & 0.57 \\
Cholesterol mg/dL & $213 \pm 48.6$ & $211 \pm 40.9$ & 0.74 \\
LDL-c mg/dL & $134 \pm 45.1$ & $132 \pm 34.8$ & 0.68 \\
HDL-c mg/dL & $42 \pm 9.2$ & $42 \pm 10.2$ & 0.82 \\
Triglycerides mg/dL & $175 \pm 122$ & $187 \pm 111$ & 0.52 \\
3-Vessel CAD n (\%) & $73(84.9)$ & $67(74.4)$ & 0.09 \\
\hline
\end{tabular}

$\mathrm{CABG}=$ coronary artery bypass graft; $\mathrm{MI}=$ myocardial infarction; $\mathrm{CCS}=$ Canadian Cardiovascular Society; $\mathrm{CAD}=$ coronary artery disease.

pump group. There was no crossover between study groups and there was no lost of follow-up. The median follow-up was 5 years.

Patients randomized to on-pump CABG were more likely to achieve complete revascularization than offpump CABG with a non-significant trend, (52.3\%) vs $(38.9 \%) \mathrm{p}=0.096$, respectively. There was no difference in the amount of grafts of left internal thoracic artery in the two revascularization strategies: $81(94.2 \%)$ vs 88 (97.8\%) for on-pump and off-pump CABG respectively $(P=0.27)$. Moreover, patients undergoing onpump surgery showed a higher average total number of grafts $2.9 \pm 0.64$ vs $2.6 \pm 0.61, P=0.002$ and a higher number of vessels treated $3.0 \pm 0.71$ vs $2.7 \pm$ $0.68, P=0.001$.

On the short-term end point, the univariate analysis demonstrated that on-pump CABG patients had a higher incidence of combined events before discharge or within 30 days after the procedure as compared with off-pump CABG: 13 (15.1\%) vs 5 (5.6\%); $P=0,04$ (Table 2) (Table 3). After the multivariate analysis, with the inclusion of the following variables: on-pump surgery, current smoke and age, performing on-pump CABG showed a trend for association with the shortterm combined end point, $\mathrm{p}=0.05$.

After 5-year follow-up, on the univariate analysis, there were no significant differences between both strategies of CABG in the composite end points 15 (16.7\%) vs 13 (15.1\%), (Hazard Ratio 1.07; CI 0.41 1.82 ; $P=0.71)$ for off-pump and on-pump CABG respectively (Figure 1).
Table 2 Univariate predictors of short-term combined events

\begin{tabular}{lccc}
\hline & $\begin{array}{c}\text { With combined } \\
\text { events } \mathbf{n = 1 8}\end{array}$ & $\begin{array}{c}\text { Without combined } \\
\text { events } \mathbf{n = 1 5 8}\end{array}$ & $\mathbf{P}$ \\
\hline On-pump CABG n (\%) & $13(72.2)$ & $73(46.2)$ & 0.04 \\
Age, years & $65.3 \pm 4.2$ & $67.4 \pm 5.2$ & 0.10 \\
Male gender n (\%) & $11(61.1)$ & $115(72.8)$ & 0.41 \\
Hypertension n (\%) & $14(77.8)$ & $105(66.5)$ & 0.43 \\
Diabetes n (\%) & $4(22.2)$ & $57(36.1)$ & 0.30 \\
Current smoke n (\%) & $6(33.3)$ & $25(15.8)$ & 0.10 \\
Angina n (\%) & $11(61.1)$ & $115(72.8)$ & 0.41 \\
3-Vessel CAD n (\%) & $16(88.9)$ & $124(78.5)$ & 0.37 \\
Previous MI n (\%) & $17(94.4)$ & $148(93.7)$ & 1.0 \\
Grafts, mean & $2.9 \pm 0.58$ & $2.7 \pm 0.65$ & 0.25 \\
Treated vessels, mean & $3 \pm 0.59$ & $2.8 \pm 0.74$ & 0.38 \\
LIMA graft n (\%) & $17(94.4)$ & $152(96.2)$ & 0.53 \\
\hline CABG = coronary artery bypass graft; MI = myocardial infarction; CAD = coronary \\
artery disease; LIMA = Left Internal Mammary Artery.
\end{tabular}

\section{Discussion}

There is currently an attempt to compare clinical outcomes in the two techniques of myocardial revascularization, on short and long-term follow-up. So far, previous studies have either underrepresented an elderly high-risk population or had lack of data on long-term follow-up.

In this post hoc analysis, we seek to evaluate a population at higher surgical risk selected by having over 60 years old at the time of randomization, and assess whether offpump CABG add clinical benefit specifically on 5-year follow-up.

In the Rooby Trial, with follow-up results available so far 1 year, both techniques had similar clinical events at 30 days but with a lower rate of combined events at 1 year favoring the on-pump group [1].

The CORONARY study aimed to compare the two techniques in a population of greater surgical risk (older patients with a higher cardiovascular risk), showing no difference in clinical events at 30 days and 1-year follow-up [2].

The MASS-3 was a randomized, single-center study that evaluated two strategies for elective CABG in patients with stable coronary artery disease and preserved ventricular function. The main result was that there was

\section{Table 3 Events at 30 days}

\begin{tabular}{lccc}
\hline & On-pump CABG & Off-pump CABG & $\boldsymbol{P}$ \\
\hline Myocardial infarction n (\%) & $10(11.6)$ & $4(4.4)$ & 0.09 \\
Stroke n (\%) & $3(4.4)$ & $1(1.1)$ & 0.36 \\
Death n (\%) & 0 & 0 & - \\
Combined events n (\%) & $13(15.1)$ & $5(5.6)$ & 0.04 \\
\hline
\end{tabular}

CABG = coronary artery bypass graft. 


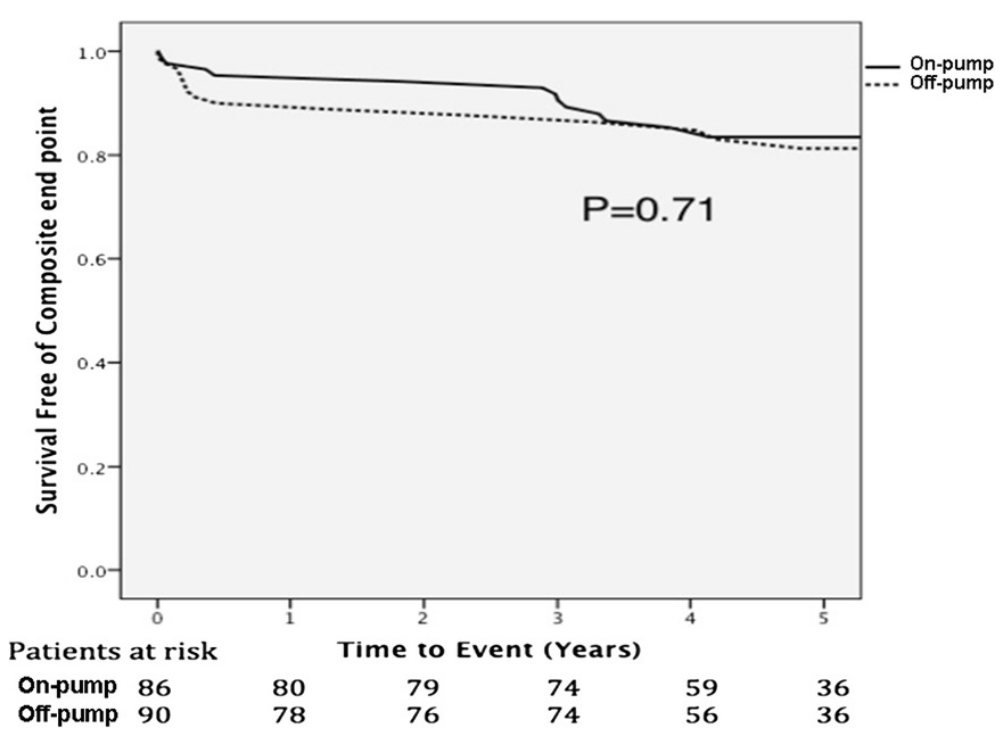

Figure 1 Kaplan-Meier estimates of survival free of combined events after surgery.

no difference in the combined end point between the two groups following 5 years [3].

Specifically in the population with advanced age, the recent studies GOPCABE and DOORS, showed no difference in clinical events on short and intermediate followup $[5,6]$.

Despite being a post-hoc analysis in a specific population of the original trial, both study groups had wellbalanced baseline characteristics. Most of our patients had 3 -vessel CAD and complete revascularization was the goal in both groups, but like previous studies, off-pump surgery was associated with a lower proportion of complete revascularization. This was evidenced by a lower average in total number of grafts and number of vessels treated on the off-pump group.

In the 30-day analysis, patients undergoing off-pump surgery had a lower incidence of combined events on the univariate analysis, driven by a lower rate of stroke and myocardial infarction. However, after the multivariate model, this analysis lost statistical significance revealing only a trend towards association.

There is some contradictory data in the literature assessing however off-pump CABG in patients with advanced age can significantly reduce rates of perioperative overall complications. Observational studies have suggested that off-pump technique might prevent stroke and postoperative myocardial infarction [13-17]. However, more recent trials did not confirm any benefit for any technique over the other on rates of in-hospital complications $[5,6]$.

The results of 5-year follow-up confirm the data obtained in previous studies with short to intermediate follow-up that both techniques are safe and similar in terms of clinical events in patients with advanced age.

The strength of this study lies on the long-term followup in a population with a higher surgical risk, with no loss to follow-up.

There were some limitations. First, we used the cut-off level of troponin and CK-MB for the diagnosis of myocardial infarction after the procedure of 5 times the 99th percentile, consistent with the definition used at the time of the study, which is a lower limit than current recommendations of the third definition of myocardial infarction [18]. Although we selected only patients older than 60 years at the time of randomization, the average age of our patients was not very high. There was only assessment of clinical outcomes of our patients, as graft patency and neurocognitive evaluation were not assessed in this study. In addition, there is no data concerning stenosis of carotid artery and cerebrovascular history for comparison between the two groups. Finally, this posthoc analysis was not pre-specified in the original design of the MASS III Trial and therefore, subject to the biases inherent of this analysis.

\section{Conclusion}

In our study, patients older than 60 years undergoing coronary surgical revascularization achieved similar rates of composite end points on short-term and long-term follow-up with on-pump and off-pump CABG.

\section{Competing interests}

The authors declare that they have no competing interests. 


\section{Authors' contributions}

Substantial contributions to the conception and design (RMVM, WH, PCR); Acquisition of the data (PCR, EGL, ACH). Analysis of the data (RMVM, PCR). Interpretation of the data (RMVM, WH, PCR, JAFR, RKF). Drafting of the article (RMVM, WH, PCR). Critical revision for important intellectual content $(\mathrm{WH}$, JAFR, RKF). All authors read and approved the final manuscript.

\section{Acknowledgments}

We would like to thank all members of the MASS III Trial for hard work in putting together all the forces in order to performing this study. This study was funded partially by Zerbini Foundation. Responsibility for opinions, conclusions and interpretation of data lies with the authors.

\section{Funding}

This work was supported by the Zerbini Foundation.

\section{Author details}

${ }^{1}$ Heart Institute (InCor) University of Sao Paulo, Sao Paulo, Brazil. ${ }^{2}$ Department of Atherosclerosis, Heart Institute of the University of Sao Paulo, Sao Paulo, Brazil. ${ }^{3} \mathrm{Av}$. Dr. Eneas de Carvalho Aguiar 44, AB, Sala 114, Cerqueira César, CEP 05403-000 São Paulo, SP, Brazil. ${ }^{4}$ Hospital Alemao Oswaldo Cruz, Sao Paulo, Brazil.

Received: 17 March 2014 Accepted: 16 June 2014

Published: 5 August 2014

\section{References}

1. Shroyer AL, Grover FL, Hattler B, Collins JF, McDonald GO, Kozora E, Lucke JC, Baltz JH, Novitzky D: On-pump versus off-pump coronary artery bypass surgery. N Engl J Med 2009, 361:1827-37.

2. Lamy A, Devereaux PJ, Prabhakaran D, Taggart DP, Hu S, Paolasso E, Straka Z, Piegas LS, Akar AR, Jain AR, Noiseux N, Padmanabhan C, Bahamondes JC, Novick RJ, Vaijyanath P, Reddy S, Tao L, Olavegogeascoechea PA, Airan B, Sulling TA, Whitlock RP, Ou Y, Ng J, Chrolavicius S, Yusuf S: Effects of off-pump and on-pump coronary-artery bypass grafting at 1 year. N Engl J Med 2013, 368(13):1179-88.

3. Hueb W, Lopes NH, Pereira AC, Hueb AC, Soares PR, Favarato D, Vieira RD, Lima EG, Garzillo CL: Paulitch Fda S, César LA, Gersh BJ, Ramires JA: Five-year follow-up of a randomized comparison between off-pump and on-pump stable multivessel coronary artery bypass grafting. Circulation 2010, 122:S48-S52.

4. Sharony R, Bizekis CS, Kanchuger M, Galloway AC, Saunders PC, Applebaum R, Schwartz CF, Ribakove GH, Culliford AT, Baumann FG, Kronzon I, Colvin SB, Grossi EA: Off-pump coronary artery bypass grafting reduces mortality and stroke in patients with atheromatous aortas: a case control study. Circulation 2003, 108:I-15-\|-20.

5. Diegeler A, Börgermann J, Kappert U, Breuer M, Böning A, Ursulescu A Rastan A, Holzhey D, Treede H, Rieß FC, Veeckmann P, Asfoor A, Reents W, Zacher M, Hilker M: Off-pump versus on-pump coronary-artery bypass grafting in elderly patients. N Engl J Med 2013, 368(13):1189-98.

6. Houlind K, Kjeldsen BJ, Madsen SN, Rasmussen BS, Holme SJ, Nielsen PH, Mortensen PE: On-pump versus off-pump coronary artery bypass surgery in elderly patients: results from the Danish on-pump versus off-pump randomization study. Circulation 2012, 125:2431-2439.

7. Natarajan A, Samadian S, Clark S: Coronary artery bypass surgery in elderly people. Postgrad Med J 2007, 83:154-158.

8. Hedeshian MH, Namour N, Dziadik E, Stewart RD, Campos CT: Does increasing age have a negative impact on six-month functional outcome after coronary artery bypass? Surgery 2002, 132:239-44.

9. Ivanov J, Weisel RD, David TE, Naylor CD: Fifteen-year trends in risk severity and operative mortality in elderly patients undergoing coronary artery bypass graft surgery. Circulation 1998, 97:673-80.

10. Alexander KP, Anstrom KJ, Muhlbaier LH, Grosswald RD, Smith PK, Jones RH, Peterson ED: Outcomes of cardiac surgery in patients age $>80$ years: results from the national cardiovascular network. J Am Coll Cardiol 2000, 35:731-8.

11. Hueb W, Lopes NH, Gersh BJ, Castro CC, Paulitsch FS, Oliveira SA, Dallan LA, Hueb AC, Stolf NA, Ramires JA: A randomized comparative study of patients undergoing myocardial revascularization with or without cardiopulmonary bypass surgery: the MASS III trial. Trials 2008, 9:52-58.
12. van Swieten JC, Koudstaal PJ, Visser MC, Shouten HJ, van Gijn J: Interobserver agreement for the assessment of handicap in stroke patients. Stroke 1988, 19:604-607

13. Athanasiou T, Al-Ruzzeh S, Kumar P, Crossman MC, Amrani M, Pepper JR, Del Stanbridge R, Casula R, Glenville B: Off-Pump myocardial revascularization is associated with less incidence of stroke in elderly patients. Ann Thorac Surg 2004, 77:745-53.

14. Hornero F, Martína E, Rodríguez R, Castellà M, Porras C, Romero B, Maroto L, PérezdelaSota E: Off-pump surgery in preventing perioperative stroke after coronary artery bypass grafting: a retrospective multicentre study. Eur J Cardio-Thorac 2013, 1-7.

15. Puskas JD, Williams WH, Duke PG, Staples JR, Glas KE, Marshall JJ, Leimbach M, Huber P, Garas S, Sammons BH, McCall SA, Petersen RJ, Bailey DE, Chu H, Mahoney EM, Weintraub WS, Guyton RA: Off-pump coronary artery bypass grafting provides complete revascularization with reduced myocardial injury, transfusion requirements, and length of stay: a prospective randomized comparison of two hundred unselected patients undergoing off-pump versus conventional coronary artery bypass grafting. J Thorac Cardiovasc Surg 2003, 125:797-808.

16. Cleveland JC Jr, Shroyer AL, Chen AY, Peterson E, Grover FL: Off-pump coronary artery bypass grafting decreases risk-adjusted mortality and morbidity. Ann Thorac Surg 2001, 72:1282-1289.

17. Boyd WD, Desai ND, DelRizzo DF, Novick RJ, McKenzie FN, Menkis AH: Off-pump surgery decreased postoperative complications and resource utilization in the elderly. Ann Thorac Surg 1999, 68:1490-1493.

18. Thygesen K, Alpert JS, Jaffe AS, Simoons ML, Chaitman BR, White HD: Third universal definition of myocardial infarction. J Am Coll Cardiol 2012, 60:1581-198.

doi:10.1186/1749-8090-9-127

Cite this article as: Vieira de Melo et al:: On-pump versus off-pump coronary artery bypass surgery in patients older than 60 years: five-yea follow-up of MASS III trial. Journal of Cardiothoracic Surgery 2014 9:127.

\section{Submit your next manuscript to BioMed Central and take full advantage of:}

- Convenient online submission

- Thorough peer review

- No space constraints or color figure charges

- Immediate publication on acceptance

- Inclusion in PubMed, CAS, Scopus and Google Scholar

- Research which is freely available for redistribution 